\title{
Ground effect on the aerodynamics of a NACA 0015 airfoil with a plain trailing-edge flap
}

\begin{abstract}
The ground effect on the aerodynamics of a NACA 0015 airfoil with a plain trailingedge flap was investigated experimentally at $\mathrm{Re}=1.6110^{5}$. The ground proximity led to an increased lift and nose-down pitching moment compared to their out-of-the-ground effect counterparts. The flap deployment also caused the flow separation to move further upstream, rendering to an earlier stall as the ground was approached. The amount of lift increment was, however, found to be most significant at low angles of attack and was reduced with increasing trailing-edge flap deflection. Meanwhile, the pressure drag of the flapped airfoil was reduced in ground effect. The enhanced aerodynamics of the flapped airfoil, especially in close ground proximity can greatly benefit the take-off and landing of WIG (wing-in-ground effect) craft.
\end{abstract}

Keywords: wing-in-ground effect (wig) craft, experimental aerodynamics and fluid mechanics, trailing-edge flap, low-speed aerodynamics
Volume 2 Issue I - 2018

\author{
VTremblay Dionne, $T$ Lee \\ Department of Mechanical Engineering, McGill University, \\ Canada
}

Correspondence: $T$ Lee, Department of Mechanical Engineering, McGill University 817 Sherbrooke St West, Montreal, Quebec, H3A 2K6, Canada, Email tim.lee@mcgill.ca

Received: August 31, 2017| Published: January 25, 2018
Abbreviations: $\mathrm{C}$, chord; $u_{\infty}$, free stream velocity; $\mathrm{V}$, kinematic viscosity; Re, chord reynolds number, $\left(=u_{\infty} c / n\right)$. OGE, out of the ground effect; $\mathrm{GE}$, ground effect; $\mathrm{C}_{\mathrm{d}}$, sectionál drag coefficient; $\mathrm{C}_{\mathrm{dp}}$, sectional pressure drag coefficient; $\mathrm{C}_{1}$, sectional lift coefficient; $\mathrm{C}_{1, \max }$, maximum $\mathrm{C}_{1} ; C_{l \alpha}$, lift-curve slope; $\mathrm{C}_{\mathrm{m}}$, sectional pitching moment coefficient; $\mathrm{C}_{\mathrm{m} \text {,peak }}$, peak $\mathrm{C}_{\mathrm{m}}$, value; $p_{\infty}$, freestream pressure; $\mathrm{C}_{\mathrm{p}}$, surface pressure coefficient, $\left(=\left(p-p_{\infty}\right) / 1 / 2 \rho u_{\infty}{ }^{2}\right)$. TEF. trailing-edge Flap; $h$, distance between airfoil trailing edge and ground; $h^{\prime}$, distance between flapped TEF and ground; $\delta_{T E}$, trailingedge flap deflection angle; $\alpha$, angle of attack; $\alpha_{s s}$, static-stall angle.

\section{Introduction}

It is known that for aircraft flying in close ground proximity, for example, during landing and takeoff, can generate a considerable lift augmentation and lift-induced drag reduction and, more importantly, a greatly enhanced lift-to-drag ratio as compared to aircraft flying out of the ground effect. The ground effect-induced lift augmentation can be attributed to the dynamic air cushion phenomenon or the so-called RAM pressure created between the wing's lower surface and the ground, while the lift-induced drag reduction is caused by the suppression of downwash angle and strength as well as to the increased effective aspect ratio in ground effect. The resulting high lift-to-drag ratio of the WIG (wing-in-ground effect) craft thus lead to an increased flight range with a lower specific fuel consumption, and has therefore attracted considerable attention in potential civil and military applications. The Russian Ekranoplan-type WIG craft, with large square wings and a small aspect ratio, were particularly designed and constructed to utilize the above-mentioned beneficial ground effect. To overcome the poor longitudinal stability, a large horizontal stabilizer mounted high and operated out of the ground effect is, however, required by the Ekranoplan WIG craft. Additionally, the power augmented ram (PAR) wings and large trailing-edge flaps were also employed to overcome the "hump drag" during the takeoff. The PAR wing concept directs the exhaust air from the engines under the main wings to generate more lift, but greatly complicates the WIG craft system. Extensive investigations have been conducted to quantify the stability ${ }^{1-3}$ and aerodynamics ${ }^{4-12}$ of rectangular NACA wings, of various airfoil profiles, in ground effect. A most recent study of the ground effect on the aerodynamics of a NACA 0012 airfoil, both stationary and unsteady, was given by Lee et al. ${ }^{12} \mathrm{An}$ in-depth review on the Ekranoplan-type WIG craft was given by Rozhdestvensky. ${ }^{13}$ In this study, only the research work related to trailing-edge flaps in ground effect was discussed.

The trailing-edge flap has been employed extensively to alter camber in the trailing-edge region and to adjust longitudinal stability, as well as to augment the lift, especially during landing and takeoff. Only limited archived research publications have, however, been devoted to rectangular wings or airfoils in ground effect. ${ }^{14,15}$ Note that the aerodynamic characteristics of inverted front wings, with or without trailing-edge flaps, of Formula One race cars in ground effect have been investigated by the research group at the University of Southampton. ${ }^{16,17}$ It was found that the downforce increased asymmetrically with a reduction in height and that the maximum downforce was dictated by gains in downforce from lower-surface suction increases and losses in downforce caused by upper-surface pressure. Also, for large flap angles there was a sharp reduction just beyond the maximum, mainly because of the boundary layer separating, and a resultant loss of circulation on the main element.

Steinbach et al. ${ }^{14}$ studied the flaps and slats both numerically and experimentally on the wing's aerodynamics and found that wing systems with excessive flap-slat mechanization were often unfavorable in the distant ground effect as the wing effective camber produced a negative ground effect. They also showed that as a highlift airfoil with a flap approached the ground, the flap efficiency decreased and the separation point moved further upstream. As the airfoil further approached the ground, the flap was shown to provide improved aerodynamic properties. Unlike the lift, the drag was shown to be significantly higher for the out of ground case, while reducing in ground proximity. Overall, the lift and drag increased with the angle of attack $\alpha$, while in some regions the use of flap in weak ground effect yielded a smaller lift than in the out of ground case. Meanwhile, the pressure was found to drop slightly near the leading edge of the 
airfoil, while rose near the trailing edge which thereby caused flow separation at a low $\alpha$ than for an airfoil in a free stream.

Ockfen et al., ${ }^{15}$ investigated experimentally the ground proximity (for $\mathrm{h} / \mathrm{c}=5 \%$ to $15 \%$ ) on the aerodynamic properties of a NACA 4412 with a plain trailing-edge flap (TEF) at $\alpha=2^{\circ}$ and $6^{\circ}$ for $\mathrm{Re}=10^{6}$ They observed that the TEF deflection increased the amount of flow trapped underneath the airfoil, leading to a considerable slowdown of the flow speed in this region and subsequently a large pressure recovery beneath the airfoil. The amount of lift augmentation due to the flap, however, appeared to lessen as the flap deflection was increased. Therefore, deflecting the flap in extreme ground effect was very effective with small deflections, while the benefit of further deflecting the flap yielded a diminishing gain. They further oberved that the drag coefficient was also increased with flap deflection, as a result of the pressure drag produced by the TEF deflection-caused increased area perpendicular to the flow coupled with the RAM pressure. Additionally, the nose-down pitching moment was also found to increase with reducing ground clearance, as a consequence of the larger pressure beneath the airfoil acting agaisnt the increased area of the blunt flap. Finally, the lift-to-drag ratio was also improved in ground effect, which is one of the selling points of WIG craft.

In summary, the deployment of a plain trailing-edge flap, especially in extreme ground effect region, is known to be the most beneficial aerodynamic properties for WIG craft. However, only limited published investigations, covering for $\mathrm{h} / \mathrm{c}=5$ to $15 \%$ at limited $\alpha$, have been conducted by researchers elsewhere. There is still a great need for a more extensive measurement covering a wide range of ground clearance (i.e., between $0 \%$ and $60 \%$ ) and $\alpha$. The objective of this study was therefore aimed at quantifying the aerodynamics of a NACA 0015 airfoil, equipped with a $25 \%$ c plain trailing-edge flap, for $0 \% \leq \mathrm{h} / \mathrm{c} \leq 60 \%$ at $\alpha=2^{\circ}$ to $16^{\circ}$ through surface pressure measurements. Aerodynamic properties of both the flapped and unflapped airfoils operating out of ground effect were also obtained to serve as a comparison.

\section{Materials and methods}

The experiment was conducted in the $0.9 \mathrm{~m} \times 1.2 \mathrm{~m} \times 2.7 \mathrm{~m}$ suctiontype wind tunnel at McGill University at $\mathrm{Re}=1.61 \times 10^{5}$. A rectangular NC-machined aluminum NACA 0015 airfoil with a chord $\mathrm{c}=25.4 \mathrm{~cm}$ and a span $b=37.5 \mathrm{~cm}$ was used as the test model. The airfoil model was also equipped with a plain trailing-edge flap of a length of $25 \% \mathrm{c}$. The

Table I NACA 00I5 orifice locations (before TEF deflection) origin of the coordinates was located at the leading edge of the airfoil. The airfoil was pitched at 1/4-chord location. The wing model was mounted between two vertical Plexiglas walls. A moveable Plexiglas plate with a 25-deg sharp leading edge was used to simulate the ground effect. ${ }^{12}$ The schematic of the airfoil model and the definition of the ground clearance are given in Figure 1A. The fixed ground method was adopted based on its simplicity. To simulate the actual flow conditions encountered when a WIG wing flies close the ground, the moving wall method, e.g., the moving-belt method employed by Ahmed et al., ${ }^{8}$ should be considered.

The airfoil model was also equipped with 48 0.35-mm-diameter pressure orifices, distributed both along the upper and bottom surfaces of the airfoil (Figure 1B), which were connected to a 48port Scanivalve system in conjunction with an YQCH-250-1 pressure transducer via $22-\mathrm{cm}$ long and $0.75-\mathrm{mm}$ i.d. plastic tubings. The location of the pressure orifices is given in Table 1. The aerodynamic load coefficients were obtained through the integration of the surface pressure distributions. The uncertainty of the surface pressure coefficient $\mathrm{C}_{\mathrm{p}}$ measurements was estimated to be \pm 0.013 .

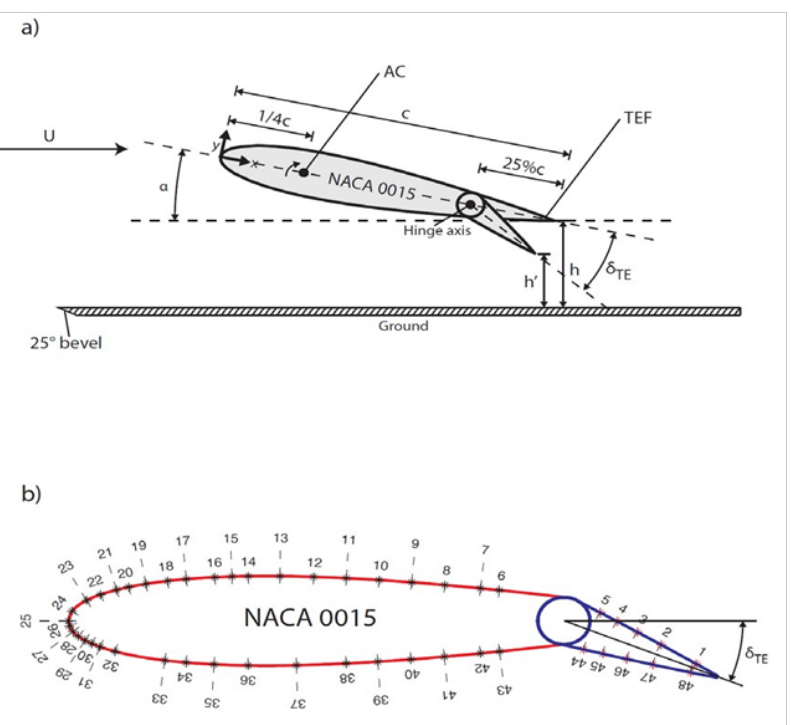

Figure I (a) Schematic of the airfoil model and definitions of trailing-edge flap deflection $\delta_{\mathrm{TE}}$ and ground clearance $\left(h\right.$ and $\left.h^{\prime}\right)$, and (b) pressure orifice locations.

\begin{tabular}{llllllll}
\hline$\#$ & $\mathbf{x} / \mathbf{c}$ & $\mathbf{y} / \mathbf{c}$ & Angle $\left({ }^{\circ}\right)$ & $\#$ & $\mathbf{x} / \mathbf{c}$ & $\mathbf{y} / \mathbf{c}$ & Angle $\left({ }^{\circ}\right)$ \\
\hline 1 & 0.9626 & 0.008 & 80.49 & 25 & 0 & 0 & 180 \\
2 & 0.9013 & 0.0179 & 81.14 & 26 & 0.0015 & -0.0084 & -160.31 \\
3 & 0.86 & 0.0242 & 81.55 & 27 & 0.0071 & -0.0181 & -140.66 \\
4 & 0.825 & 0.0293 & 81.88 & 28 & 0.0152 & -0.0259 & -128.73 \\
5 & 0.7957 & 0.0334 & 82.16 & 29 & 0.0255 & -0.033 & -120.55 \\
6 & 0.6523 & 0.0514 & 83.55 & 30 & 0.0358 & -0.0384 & -115.46 \\
7 & 0.6238 & 0.0545 & 83.86 & 31 & 0.0483 & -0.0438 & -111.2 \\
8 & 0.5698 & 0.06 & 84.51 & 32 & 0.071 & -0.0514 & -106.12 \\
9 & 0.5197 & 0.0646 & 85.19 & 33 & 0.1462 & -0.0663 & -97.53 \\
10 & 0.4703 & 0.0684 & 85.97 & 34 & 0.1781 & -0.0699 & -95.36 \\
\hline
\end{tabular}


Table Continues...

\begin{tabular}{llllllll}
$\#$ & $\mathbf{x} / \mathbf{c}$ & $\mathbf{y} / \mathbf{c}$ & Angle $\left(^{\circ}\right)$ & $\#$ & $\mathbf{x} / \mathbf{c}$ & $\mathbf{y} / \mathbf{c}$ & Angle $\left(^{\circ}\right)$ \\
\hline 11 & 0.4209 & 0.0715 & 86.89 & 35 & 0.2207 & -0.073 & -93.09 \\
12 & 0.3712 & 0.0737 & 87.99 & 36 & 0.272 & -0.0748 & -90.96 \\
13 & 0.3205 & 0.0749 & 89.36 & 37 & 0.3454 & -0.0745 & -88.65 \\
14 & 0.2724 & 0.0748 & 90.95 & 38 & 0.4205 & -0.0715 & -86.9 \\
15 & 0.2476 & 0.0742 & 91.9 & 39 & 0.4684 & -0.0685 & -86.01 \\
16 & 0.2219 & 0.0731 & 93.04 & 40 & 0.5185 & -0.0647 & -85.21 \\
17 & 0.1787 & 0.07 & 95.33 & 41 & 0.569 & -0.0601 & -84.52 \\
18 & 0.1505 & 0.0669 & 97.22 & 42 & 0.6237 & -0.0546 & -83.86 \\
19 & 0.1176 & 0.0619 & 100.01 & 43 & 0.6525 & -0.0514 & -83.55 \\
20 & 0.0915 & 0.0567 & 102.97 & 44 & 0.7958 & -0.0334 & -82.16 \\
21 & 0.0732 & 0.052 & 105.74 & 45 & 0.8251 & -0.0293 & -81.88 \\
22 & 0.049 & 0.0441 & 111 & 46 & 0.8623 & -0.0238 & -81.53 \\
23 & 0.0278 & 0.0343 & 119.22 & 47 & 0.9025 & -0.0177 & -81.13 \\
24 & 0.0057 & 0.0163 & 143.98 & 48 & 0.9599 & -0.0084 & -80.52 \\
\hline
\end{tabular}

\section{Result and discussion}

Before the discussion of the flapped NACA 0015 airfoil (i.e., with trailing-edge flap deflection) in ground effect, the aerodynamics of the unflapped airfoil is discussed first.

\section{Unflapped airfoil in ground effect}

Figure 2A shows the variation of $\mathrm{C}_{1}$ of the unflapped NACA 0015 airfoil with $\mathrm{h} / \mathrm{c}(=0 \%$ to $60 \%)$ at $\alpha=2^{\circ}$ to $16^{\circ}$. The baseline airfoil (i.e., in a free stream or operating out of the ground effect), with a static-stall angle $\alpha_{s s}$ of $15^{\circ}$ and $\mathrm{C}_{1 \max }$ of 1.09 , was also included in this figure for a direct comparison. In ground effect, there was an increase in the lift-curve slope $C_{l \alpha}$ compared to the baseline airfoil. The smaller the $\mathrm{h} / \mathrm{c}$ the larger the $C_{l \alpha}$ became. The $\mathrm{C}_{1}$, however, had a negative value for $\alpha \leq 3^{\circ}$, due to the Venturi or convergingdiverging flow passage developed underneath the NACA 0015 airfoil and the ensuing suction pressure build-up on the airfoil's lower surface (see the blue line in Figure 2B). Also, the smaller the $\mathrm{h} / \mathrm{c}$ the more negative the $\mathrm{C}_{1}$ became. For $3^{o}<\alpha \leq \alpha_{s s}$, the $\mathrm{C}_{1}$ value was found to increase above the out-of-the-ground effect value, mainly due to the RAM pressure acted on the airfoil's lower surface (see, for example, at $\alpha=10^{\circ}$ in Figure 2B). The smaller the $\mathrm{h} / \mathrm{c}$ the higher the RAM pressure or lift was achieved. Note that for $\mathrm{h} / \mathrm{c} \geq 60 \%$, the change in $\mathrm{C}_{1}$ became marginal.

The $\mathrm{C}_{\mathrm{p}}$ measurements further indicate that the suction pressure, including the suction peak, developed on the airfoil's upper surface was lower than the baseline-airfoil value for all $\alpha\left(<\alpha_{s s}\right)$ and $\mathrm{h} / \mathrm{c}$ tested in the present study. There was also a loss of suction pressure increase near the trailing edge of the NACA 0015 airfoil's upper surface as the ground was approached, suggesting an increased adverse $\mathrm{dp} / \mathrm{dx}$ and, subsequently, an earlier flow separation compared to the baseline airfoil (Figure 2B). The smaller the $\mathrm{h} / \mathrm{c}$ the earlier the stall for $\mathrm{h} / \mathrm{c} \leq 60 \%$ tested. For $\mathrm{h} / \mathrm{c}=5 \%$, the $\alpha_{s s}$ remained basically unchanged. The change in the suction pressure on the airfoil's upper surface was also found to be insensitive to $\mathrm{h} / \mathrm{c}$ for $\alpha>3^{\circ}$.

Figure $2 \mathrm{C}$ shows that the $\mathrm{C}_{\mathrm{d}}$ was also found to be a weak function of $\mathrm{h} / \mathrm{c}$; i.e., the $\mathrm{C}_{\mathrm{d}}$ remained close to the baseline-airfoil value for $\alpha<\alpha_{\mathrm{ss}}$ in ground effect. The $\mathrm{C}_{1}$ augmentation thus led to an improved $\mathrm{C}_{\mathrm{l}} / \mathrm{C}_{\mathrm{d}}$ in ground effect for $\alpha \leq \alpha_{s s}$ (Figure 2D). There, however, exhibited a considerable increase in nose-down $\mathrm{C}_{\mathrm{m}}$ in the medium-tohigh $\alpha$ regime as the ground was approached (Figure 2E); a major drawback of WIG craft. To better quantify the impactful ground effect on the lift production, the increment $\mathrm{C}_{1}$ (i.e., $\Delta C_{l}=C_{l, G E}-C_{l, O G E}$, where GE and OGE denote ground effect and out of the ground effect, respectively) as a function of $\mathrm{h} / \mathrm{c}$ at each $\alpha$ is also presented in Figure $2 \mathrm{~F}$. As can be seen, the ground proximity had a greater impact on $\mathrm{C}_{1}$ of the unflapped airfoil at higher $\alpha$. Also, the smaller the $\mathrm{h} / \mathrm{c}$ the larger $\mathrm{C}_{1}$ increment was obtained. The ground effect, however, became less impactful for $\mathrm{h} / \mathrm{c}>10 \%$.

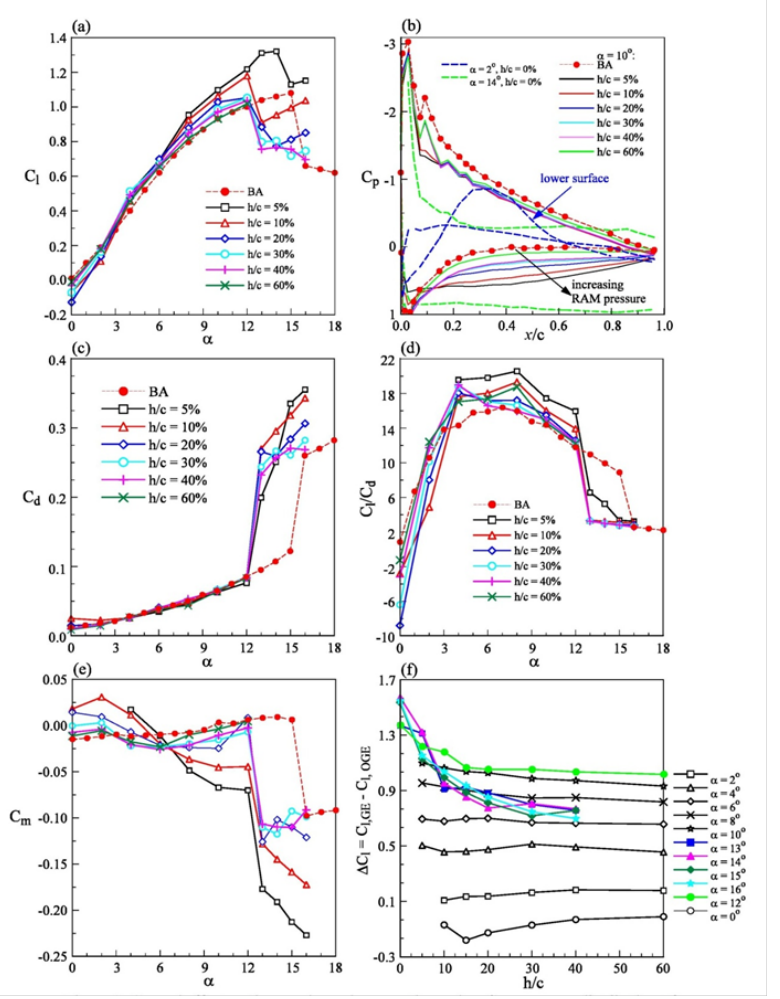

Figure 2 Ground effect of aerodynamic properties and surface pressure distribution of unflapped NACA 0015 airfoil. BA denotes base line airfoil in a free stream. 


\section{Airfoil with TEF deflection}

TEF out of ground effect: Figure $3 \mathrm{~A}$ summarizes the overall $\mathrm{C}_{1}$ behavior of the flapped NACA 0015 airfoil with $\delta_{T E}=5^{\circ}$ to $23^{\circ}$ in a free stream. The TEF deployment, in comparison with the unflapped airfoil, led to

1. Leftward shift of the $C_{l}-\alpha$ curve accompanied by a non-zero $C_{l}$ at $\alpha=0^{\circ}$;

2. A large $\mathrm{C}_{1}$ enhancement caused by the pressure increase along the airfoil (Figure 3B) and the TEF-induced positive camber;

3. A suction pressure increase (especially in the flap region), including its peak value; and

4. A promoted stall and the earlier stall, originating from the boundary-layer flow separation and the flap-caused obstruction of the stream wise flow, also resulted in a large pressure drag increase compared to the unflapped airfoil in a free stream (Figure 3C).

The pressure underneath the airfoil increased with increasing $\delta_{T E}$ The large $\mathrm{C}_{\mathrm{d}}$ increase overwhelmed the corresponding $\mathrm{C}_{1}$ increase, rendering a lowered $\mathrm{C}_{\mathrm{l}} / \mathrm{C}_{\mathrm{d}}$ ratio (Figure $3 \mathrm{D}$ ) compared to its unflapped counterpart. The TEF deflection also generated a substantial nosedown $\mathrm{C}_{\mathrm{m}}$ (Figure $3 \mathrm{E}$ ), attributing to the large pressure increase exerted on the lower side of the flap. The higher the $\delta_{T E}$ the larger the nosedown $\mathrm{C}_{\mathrm{m},} \mathrm{C}_{1}$ and $\mathrm{C}_{\mathrm{d}}$ became.

In the next section, the ground clearance $\left(\mathrm{h}^{\prime} / \mathrm{c}=0 \%\right.$ to $\left.60 \%\right)$ on the flapped NACA 0015 airfoil with different $\delta_{T E}$ is discussed. $\mathrm{h}^{\prime}$ is the distance between the trailing edge of the deflected flap and the ground as specified in Figure 1A. Special attention was placed on the immediate vicinity of the ground surface with $h^{\prime} / \mathrm{c} \leq 5 \%$, which corresponds to the main-wing TEF deployment of the Russian KM WIG craft to create a static air cushion below during takeoff by almost closing off the trailing edge against the ground plane.
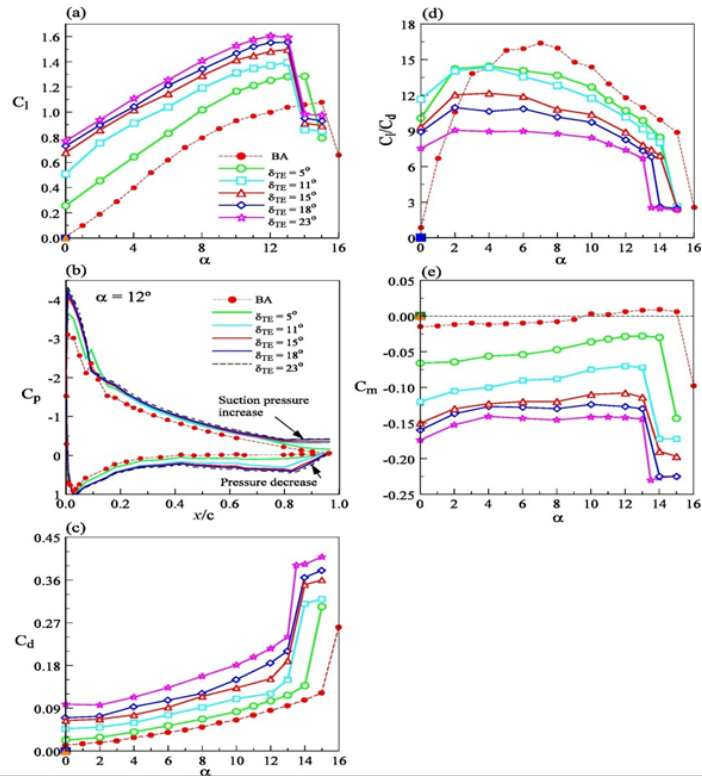

Figure 3 Aerodynamic behavior and $C_{p}$ flapped airfoil in a free stream.

TEF in ground effect: In contrast to the flapped airfoil in a free stream, the presence of the ground caused a. A further increase in $\mathrm{C}_{1}$ for all $\mathrm{h}^{\prime} / \mathrm{c}$ tested;

b. The flap deflection was most effective in the low- $\alpha$ range;

c. The relative amount of lift increment appeared to lessen as the flap deflection $\delta_{T E}$ was increased (i.e., the impact of ground proximity decreased as the flap deflection was increased);

d. A lowered $\mathrm{C}_{\mathrm{d}}$ decreased with reducing $\mathrm{h}^{\prime} / \mathrm{c}$;

e. The $\mathrm{C}_{\mathrm{l}} / \mathrm{C}_{\mathrm{d}}$ ratio and the nose-down $\mathrm{C}_{\mathrm{m}}$ increased as $\mathrm{h} / \mathrm{c}$ was decreased; and

f. A stronger adverse $d p / d x$ which together with the jet-type flow through the diminishing gap at the trailing edge led to an earlier flow separation and subsequently a promoted stall. To illustrate the ground proximity on the above-mentioned observations, the aerodynamic properties and the $\mathrm{C}_{\mathrm{n}}$ distributions for the $\delta_{T E}=23^{\circ}$ flap deflection were discussed first, followed by the $\delta_{T E}=5^{\circ}$ deflection.

Figure 4A demonstrates that for $\delta_{T E}=23^{\circ}$ deflection the $\mathrm{C}_{1}$ was increased with reducing $\mathrm{h}^{\prime} / \mathrm{c}$ (up to $\alpha_{\mathrm{ss}}$ ) compared to its out-of-theground effect counterpart, as a result of the increased amount of flow slowed down and/or trapped underneath the flapped airfoil and the subsequent RAM pressure increase (see, for example at $\alpha=8^{\circ}$ and $10^{\circ}$ presented in Figure $5(\mathrm{~A} \& \mathrm{~B})$. At a fixed $\delta_{T E}$, the ground proximity on the flapped airfoil was most beneficial at low $\alpha$ (Figure 4B); i.e., the observed relative $\mathrm{C}_{1}$ increment decreased rapidly as $\alpha$ was increased. Figure 4B also indicates that at a fixed $\alpha\left(\right.$ for $\left.\alpha<\alpha_{s s}\right)$ the $\mathrm{C}_{1}$ increment decreased significantly with increasing $\mathrm{h}^{\prime} / \mathrm{c}$ and that the largest $\mathrm{C}_{1}$ increment occurred in extreme ground proximity (i.e., $\mathrm{h}^{\prime} / \mathrm{c} \leq 10 \%$ ) and became much less significant for $\mathrm{h}^{\prime} / \mathrm{c}>20 \%$. For at the limiting $\mathrm{h}^{\prime} / \mathrm{c}=0 \%$ case, the $\alpha_{\mathrm{ss}}$ remained virtually unchanged compared to the flapped airfoil in a free stream. For $\mathrm{h}^{\prime} / \mathrm{c} \geq 5 \%$, the flapped airfoil stalled was observed to stall before $\alpha=9^{\circ}$.

Figures $5 \mathrm{~A}$ to $5 \mathrm{~B}$ further reveal that the ground proximity also gave an increased suction peak but a lower suction pressure along the flapped airfoil's upper surface. The smaller the h'/c the large the RAM pressure and suction peak were achieved. The increased RAM pressure forced a larger amount of flow over the nose of the airfoil producing an accelerated flow over the flapped airfoil's upper surface rendering an increased suction peak. The accelerated flow however confronted an ever-increasing $\mathrm{dp} / \mathrm{dx}$ as it traveled downstream leading to an earlier stall. The increased $d p / d x>0$ gradient can be reflected from the suction pressure decrease on the upper surface of the flapped airfoil (e.g., at $\alpha=8^{\circ}$ in Figure 5A). Figure 5B that the $\mathrm{C}_{\mathrm{p}}$ had an almost constant +1.0 value on the airfoil's lower surface (denoted by the black line) for the limiting $\mathrm{h}^{\prime} / \mathrm{c}=0 \%$ condition, and that the flapped airfoil reached an earlier for $h / c>10 \%$ as demonstrated by the flat $C_{p}$ distribution along the airfoil's upper surface.

Figure $4 \mathrm{c}$ reveals that in ground effect there was a reduction in $\mathrm{C}_{\mathrm{d}}$ of the flapped airfoil compared to the no-ground effect value for $\alpha \leq \alpha_{s s}$, which can be attributed to the ground effect-induced flow acceleration in the leading-edge region of the flapped airfoil which allowed the flow to remain further attached for $\alpha \leq \alpha_{s s}$. The $\mathrm{C}_{\mathrm{d}}$ reduction, however, appeared to be insensitive to $h^{\prime} / \mathrm{c}$. The $\mathrm{C}_{1}$ increase and $\mathrm{C}_{\mathrm{d}}$ reduction of the flapped airfoil in ground effect always produced an increased $\mathrm{C}_{1} / \mathrm{C}_{\mathrm{d}}$ ratio for $\alpha \leq \alpha_{s s}$ (Figure 4D). Despite of the favorable impact on $\mathrm{C}_{\mathrm{l}}, \mathrm{C}_{\mathrm{d}}$ and $\mathrm{C}_{\mathrm{l}} / \mathrm{C}_{\mathrm{d}}$, the ground proximity also led to a further increase in the nose-down $\mathrm{C}_{\mathrm{m}}$ (Figure 4E), which can further deteriorate the pitch stability of the flapped airfoil. 

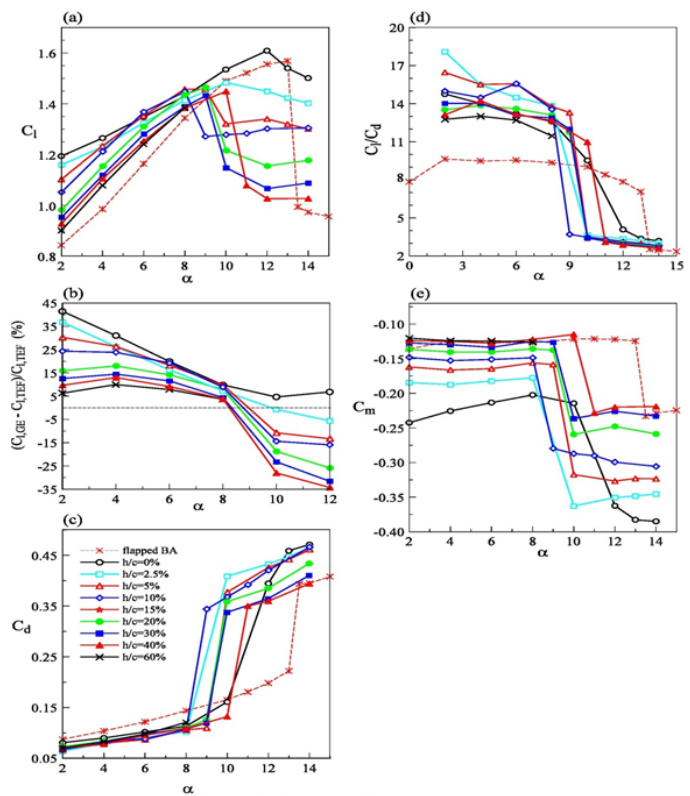

Figure 4 Ground effect on the flapped airfoil with $\delta_{T E}=23^{\circ} . \mathrm{C}_{\mathrm{I}, \mathrm{GE}}$ and $\mathrm{C}_{\mathrm{I}, \mathrm{OGE}}$ denote $C_{1}$ of the deflected airfoil in GE and OGE respectively.
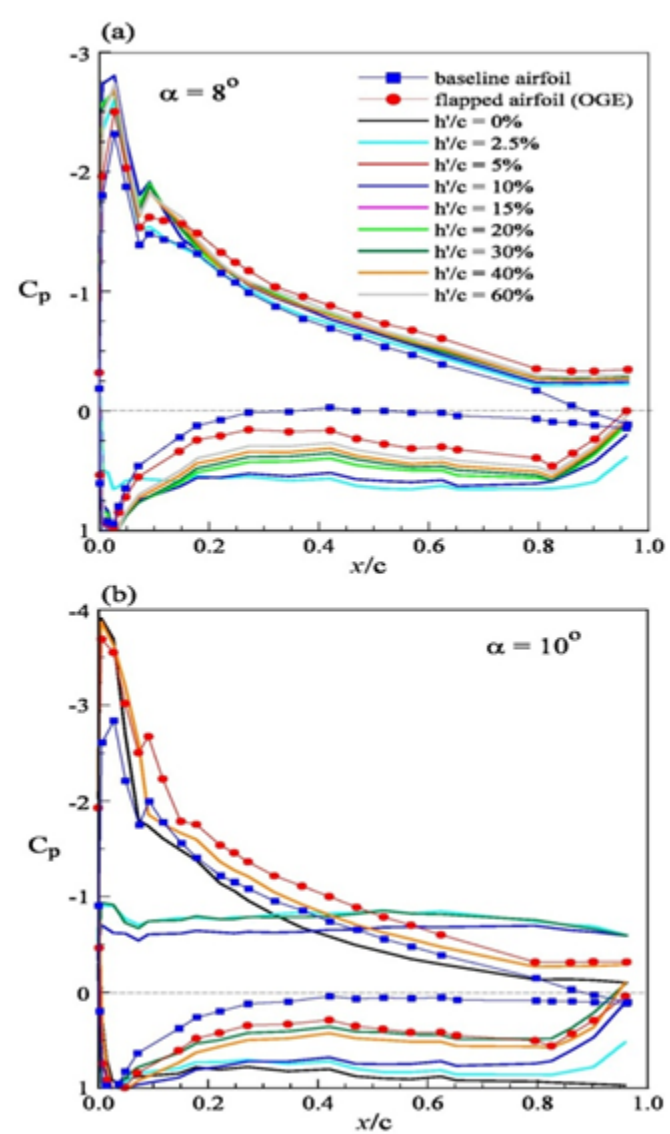

Figure 5 Surface pressure coefficient of the flapped airfoil with $\delta_{T E}=23^{\circ}$ in the ground effect.

Now, the ground effect on the flapped airfoil with $\ddot{a}_{\mathrm{TE}}=5^{\circ}$ is illustrated in Figure 6. Similar to the $\ddot{a}_{\mathrm{TE}}=5^{\circ}$ deflection, the $\mathrm{C}_{1}$ increased sharply with reducing $h^{\prime} / \mathrm{c}$, especially for $\mathrm{h}^{\prime} / \mathrm{c}<10 \%$ (Figure 6A). A $90 \%$ increase in $\mathrm{C}_{1}$ for $\mathrm{h}^{\prime} / \mathrm{c}=2.5 \%$, for example, at $\mathrm{a}=4^{\circ}$ was obtained (Figure 6B) in comparison with $26 \%$ of its $\ddot{a}_{\mathrm{TE}}=23^{\circ}$ counterparts. The $\mathrm{C}_{\mathrm{d},} \mathrm{C}_{\mathrm{l}} / \mathrm{C}_{\mathrm{d}}$ and $\mathrm{C}_{\mathrm{m}}$ were also found to increase in ground effect (Figure $6 \mathrm{c}$ to $6 \mathrm{D}$ ). The extent of $\mathrm{C}_{1}$ enhancement of the $\ddot{a}_{\mathrm{TE}}=5^{\circ}$ flap deflection was, however, of a much greater extent as compared to the $\ddot{a}_{\mathrm{TE}}=23^{\circ}$ case.

Finally, to provide a direct comparison of $\delta_{\mathrm{TE}}$ on the flapped NACA 0015 airfoil in ground effect, the aerodynamic properties at $\mathrm{h}^{\prime} / \mathrm{c}=2.5 \%$ as a function of $\ddot{\mathrm{a}}_{\mathrm{TE}}$ is presented in Figure 7 . At a fixed ground distance,
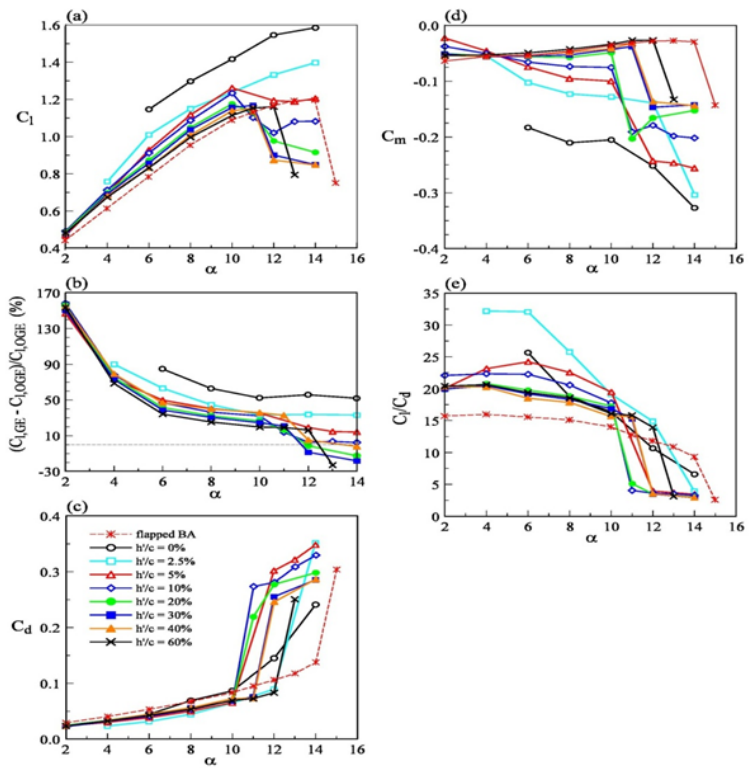

Figure 6 Ground effect on the flapped NACA 0015 airfoil with $\delta_{T E}=5^{\circ}$.
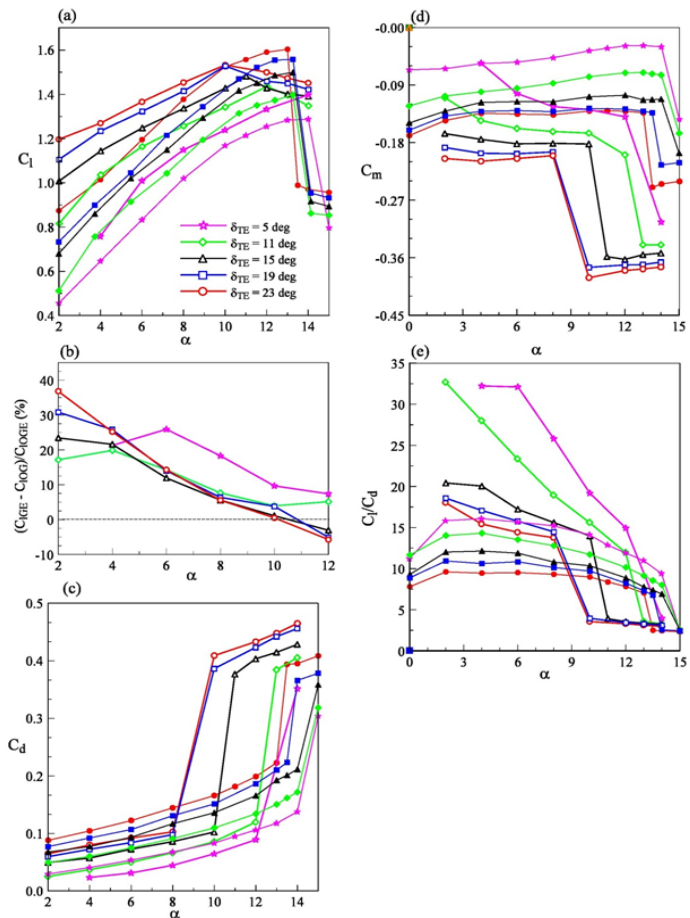

Figure 7 Variation of Aerodynamic coefficients with $\delta_{T E}$ at fixed h'/c=2.5\%. Open and solid symbols denote in ground effect and out-of-ground effect. respectively. 

7A);

The $\mathrm{C}_{1}$ was always found to increase with increasing $\ddot{a}_{\mathrm{TE}}$ (Figure

The gain in $\mathrm{C}_{1}$ increment (i.e., $\ddot{\mathrm{AC}}_{1}$ ) was diminishing as $\ddot{\mathrm{a}}_{\mathrm{TE}}$ was increased (Figure 7B);

The $\mathrm{C}_{\mathrm{d}}$ was reduced with reducing $\ddot{\mathrm{a}}_{\mathrm{TE}}$ since the pressure drag became less dominant with decreasing $\ddot{\mathrm{T}}_{\mathrm{TE}}$ (Figure $7 \mathrm{C}$ ); and

The nose-down $\mathrm{C}_{\mathrm{m}}$ decreased with decreasing $\ddot{\mathrm{a}}_{\mathrm{TE}}$, as a result of the reduced amount of flow trapped beneath the airfoil as $\ddot{a}_{\mathrm{TE}}$ was reduced (Figure 7D). In short, the smallest trailing-edge flap deflection seemed to produce not only the smallest nose-down $\mathrm{C}_{\mathrm{m}}$ and $\mathrm{C}_{\mathrm{d}}$ but also the largest $\mathrm{AC}_{1}$ and the best lift-to-drag ratio among all $\ddot{\mathrm{a}}_{\mathrm{TE}}$ tested (Figure 7E)

\section{Conclusion}

The ground effect on the aerodynamic behavior of a NACA 0015 airfoil with a plain trailing-edge flap was investigated experimentally. For the unflapped airfoil, the ground effect produced a negative lift for á $\leq 3^{\circ}$ while became positive for á $>3^{\circ}$. The lift increment was also found to increase with reducing ground distance. The ground effect, however, became less impactful for $\mathrm{h} / \mathrm{c}>15 \%$. The presence of the ground also caused an increased in the drag and nose-down pitching moment compared to their out-of-ground effect counterparts.

For the flapped airfoil in ground effect, the RAM pressure and the suction peak continued to increase as the ground was approached, attributing to the increased amounts of flow trapped underneath the airfoil. The RAM pressure and lift augmentation also increased as the trailing-edge flap was deflected. The percentage of lift increment was, however, found to be most significant in the low-á regime. The closer the ground proximity the earlier the airfoil stall was observed. Meanwhile, the drag was, however, reduced while the nose-down pitching moment was increased with reducing ground distance. Overall, smaller plain flap deflections in ground effect produced the best lift increment and lift-to-drag ratio compared to larger flap deflections. It is therefore suggested that a simple plain TEF deflected at small deflections, especially in extreme ground proximity, can greatly regulate the aerodynamic efficiency of the WIG craft.

\section{Acknowledgments}

The authors would like to thank L.S. Ko for his help with the figure preparation. This work was supported by the Natural Science and Engineering Research Council of Canada (NSERC).

\section{Conflicts of interest}

Author declares that there is no conflicts of interest.

\section{References}

1. Divitiis ND. Performance and stability of a winged vehicle in ground effect. J Aircraft. 2005;42(1):148-157.

2. Angle EM, Brian OM, Franz AP, et al. Pitch stability analysis of an airfoil in ground effect. J Aircraft. 2009;46(3):756-762.

3. Wang H, Teo CJ, Khoo BC, et al. Computational aerodynamics and flight stability of wing-in-ground (WIG) craft. Procedia Eng. 2013;67:15-24.

4. Tomaru H, Kohama Y. Experiments on wing in ground effect with fixed ground plates. Proceedings of the 2nd JSME-KSME Fluids Eng. Conference, Japan Society of Mech Engrs, Japan: Tokyo; 1990. p. 370-373.

5. Hsiun CM, Chen CK. Aerodynamic characteristics of a two-dimensional airfoil with ground effect. J Aircraft. 1996;33(2):386-392.

6. Moore N, Wilson PA, Peters AJ. An investigation into wing in ground effect airfoil geometry. In RTO-MP-095, NATO RTO, Fluid Structure Interactions Group, Symposium on Challenges in Dynamics, System Identification, Control and Handling Qualities for Land, Air, Sea and Space Vehicles, Berlin, Germany; 2002. 20 p.

7. Ahmed MR, Sharma SD. An investigation on the aerodynamics of a symmetric airfoil in ground effect. Expt Thermal \& Fluid Sci. 2005;29(6):633-647.

8. Ahmed MR, Takasaki T, Kohama Y. Aerodynamics of a NACA 4412 airfoil in ground effect. AIAA J. 2007;45(1):37-47.

9. Luo SC, Chen YS. Ground effect on flow past a wing with a NACA 0015 cross-section. Expt thermal \& Fluid Sci. 2012;40:18-28.

10. Liang H, Zhou L, Zong Z, et al. An analytical investigation of twodimensional and three-dimensional biplanes operating in the vicinity of a free surface. J Marine Sci \& Tech. 2013;18(1):12-31.

11. Liang H, Wang X, Zou L, et al. Numerical study of two-dimensional heaving airfoils in ground effect. J Fluids \& Struc. 2014;48:188-202.

12. Lee T, Majeed A, Siddiqui B, et al. Impact of ground proximity on the aerodynamic properties of an unsteady airfoil. Proceedings of the Institution of Mechanical Engineers, Part G: Journal of Aerospace Engineering. 2017.

13. Rozhdestvensky KV. Wing-in-ground effect vehicles. Prog in Aero Sci. 2006;42(3):211-283.

14. Steinbach D. Comment on "Aerodynamic characteristics of a twodimensional airfoil with ground effects". J Aircraft. 1997;34(3):455-456.

15. Ockfen AE, Matveev K. Aerodynamic characteristics of NACA 4412 airfoil section with flap in extreme ground effect. J Naval Architecture and Ocean Eng. 2009;1(1):1-12.

16. Zerihan J, Zhang X. Aerodynamics of a single-element wing in ground effect. J Aircraft. 2000;37(6):1058-1064.

17. Zhang X, Zerihan J. Aerodynamics of a double-element wing in ground effect. AIAA J. 2003;41(6):1007-1016. 